\begin{abstract}
Ruminant Rasyonlarında Doğrudan Yedirilen Mikroorganizmaların Önemi ve Etki Mekanizmaları

Mete YANAR $^{1}$

ÖZET: Ruminant yemlerine katılan Doğrudan Yedirilen Mikroorganizmalar (Direct-Fed Microbials) (DFM) olarak adlandırılan yem katkı maddeleri, sindirim sistemi enfeksiyonlarını önlediği gibi, sindirim kanalının mikroorganizma içeriğini de optimize etme kabiliyetine sahiptirler. Son yıllarda, AB ülkeleri ile Türkiye'de üretilen yemlerde antibiyotik kullanımının yasaklanmasından sonra, DFM'lerin yaygın bir şekilde yem katkı maddesi olarak yemlere ilave edildiği görülmektedir. Söz konusu DFM'lerin yem katkı maddesi olarak tarihsel gelişimi, DFM olarak kullanılan mikroorganizmalar, DFM'nin etkinliğini ve aktivitesini belirleyen faktörler ile rumen ve bağırsaklardaki etki mekanizmaları bu çalışmada detaylı olarak ele alınarak incelenmiştir.
\end{abstract}

Anahtar Kelimeler: Doğrudan yedirilen mikroorganizmalar, etki mekanizmaları ruminantlar, yem katkı maddesi

\title{
Importance of Direct-Fed Microbials in Ruminant Diets and Modes of Action
}

\begin{abstract}
Feed additives which are supplemented into the ruminants' feed and called Direct-Fed Microbials inhibit gastrointestinal infections, and have capability for optimizing of microbial content of gastrointestinal track. In recent years, after the use of antibiotics in the feeds manufactured in EU countries and Turkey has been banned, DFM are started to added into the feeds on large scale as feed supplement. In this study, historical development of DFM, microorganisms used as DFM, factors affecting efficiency and activity of the DFM as well as action modes in rumen and intestines were investigated in detail.
\end{abstract}

Keywords: Direct-fed microbials, feed supplements, modes of action, ruminants

Atatürk Üniversitesi, Ziraat Fakültesi, Zoootekni, Erzurum, Türkiye

Sorumlu yazar/Corresponding Author: Mete YANAR, mtyanar@gmail.com 


\section{GíRIŞ}

Hayvan yetiştiriciliğinde, hayvanların yüksek verim gücüne ve hayvan sağlığına sahip olması en önemli hususlardır. Hayvanların büyüme ve gelişme hızları ile besi performansları, yemden yararlanma durumları ve genel sağlık durumları sindirim sisteminin fonksiyonları ile yakından ilişkilidir. Bugün, dünyadaki birçok ülkede, çiftlik hayvanlarının verimleri ile yemden yararlanma etkinliğini yükseltmek ve hastalıklardan korumak için birçok yem katk1 maddeleri kullanılmaktadır. Antibiyotikler, probiyotikler ve prebiyotikler söz konusu katkı maddeleri içersinde en fazla tanınmış olanları olup, hayvanların rumen ve bağırsaklarındaki mikrobial ekosistem ve fermantasyon özelliklerini düzenlemek amacıyla kullanılmaktadır (Koçyiğit ve ark. 2015).

İnce bağırsaklarda mikroorganizma dengesinin olumlu yönde değiştirilmesi sonucu konakçı hayvanı faydalı yönde etkileyen canlı mikrobiyal yem katkı maddesi olarak tanımlanan probiyotikler; terim olarak canlı mikrobiyal kültürler, kültür ekstraktları, enzim preparatları ve bunların farklı kombinasyonlarını da ifade eden geniş bir anlamda, bir çok çeşit ürünü içine almaktadır (Krehbiel et al., 2003). Ancak son yıllarda bu terim Amerika Birleşik Devletleri Tarım Bakanlı̆̆ 1 tarafindan yeniden düzenlenerek yem fabrikalarının "probiyotik" ifadesi yerine "Doğrudan Yedirilen Mikroorganizmalar" (Direct-Fed Microbials) (DFM) ifadesinin kullanıma geçirilmesini zorunlu kılmıştır. DFM ile probiyotiklerin anlamı daraltılarak "doğal olarak mevcut mikroorganizmaları (bakterileri ve/veya mayaları) içeren yem katkı maddeleri” tanımlanmıştır (Seo et al., 2010). Son yıllarda çiftlik hayvanlarında antibiyotiklerin düşük dozlarda yem katkı maddesi olarak kullanımı, hayvanlardan insanlara geçebilen hastalıklara neden olan bakterilerin antibiyotiklere karşı direnç kazanmaya başlaması ile et ve sütteki antibiyotik kalıntıları ve antibiyotiklere dirençli genlerin yayılma potansiyeli kaygılarıyla başta $\mathrm{AB}$ ülkeleri olmak üzere ülkemizde dahil olmak üzere bir çok ülkede yasaklanmıştır (Diler ve ark. 2015). Bunun sonucu olarak, özellikle sığır yetiştiriciliği ve diğer hayvancılık kollarında antibiyotik ve diğer büyümeyi teşvik edici maddelere karşı artan endişe ve kaygıların sonucu yetiştiricileri DFM gibi alternatif yem katkı maddelerine yöneltmiştir (Aydın ve ark. 2008).

\section{DFM'NIN YEM KATKI MADDESİ OLARAK TARIHSEL GELIŞìi}

Bakteriyel DFM'nin kullanımına ait tarihsel bilgiler Newman and Jacques (1995) ve Krehbiel et al.,
(2003) tarafindan bildirilmiştir. İlk olarak 1908 yılında Metchnikoff tarafindan yayınlanan "The Prolongation of Life" (Hayatın Uzatılması) adlı eserde, yazar sindirim kanalında yaşayabilen Lactobasillus'ların tüketilmesinin çok faydalı olduğunu ileri sürmüştür (Yoon and Stern, 1995). Bulgarların genellikle uzun ömürlü olmalarının bir nedeni olarak ta, enteropatojenlerin neden olduğu hastalıklardan koruyucu olan, içinde Lactobacilus'ların mevcut olduğu fermente süt ürünlerini tüketmeleri gösterilmiştir. $\mathrm{Bu}$ fikir, 1920 lerde Lactobacillus türlerinin etkinliği üzerine bir çok çalışmanın yapılmasına yol açmış, ve 1930 ların ortalarında Lactobacillus acidophilus terapilerinin popülaritesi zirveye çıkmıştır. II. Dünya savaşını takiben, etkinliği çok fazla olan ve bütün bağırsak mikroorganizmalarını yok eden antibiyotiklerin kullanımının artışı ile popülaritesi azalmıştır. Yine de o yıllarda, antibiyotik kullanımının bir yan etkisi olarak, "antibiyotik ishalleri”" ndeki artışa bağlı olarak, bağırsak mikroflorasının yeniden oluşumuna yönelik Lactobacillus acidophilus tedavileri yeniden gündeme gelmiştir. 1950 lerden bu güne kadar insan ve hayvanlar için DFM lerin geliştirilmesi konusunda çalışmalar devam etmektedir (Seo et al., 2010).

\section{DFM OLARAK KULLANILAN MIKKROORGANIZMALAR}

Genel anlamda DFM olarak kullanılan bakteriler laktik asit üreten, laktik asit kullanan ve diğer mikroorganizmalar olarak sinıflandırılmaktadır (Seo et al., 2010, Anonim, 2016). Bu siniflara giren ve en yaygin DFM olarak kullanılan mikroorganizmalar ise Lactobacillus, Bifidobacterium, Enterococcus, Streptococcus, Bacillus ve Propionibacterium cinsleridir (Çizelge 1). Megasphaera elsdenii ve Prevotella bryantii gibi mikroorganizmalarda rumen fonksiyonların iyileştirmek ve stabilize etmek için DFM olarak kullanılabilmektedir.

Ruminant hayvanlarda DFM yi oluşturan mikroorganizmalar ilk olarak rumende çoğalarak, onun mikrobiyal ekosistemini ve fermentasyon özelliklerini etkiler ve değiştirir. Rumenin yanı sıra, bağırsaklarda mikroorganizmalar için ilave bir konakçı alanı oluşturur. Rumende laktik asit üretimi ve kullanımı hayvan sağlığı ve yemden yaralanma özellikleri bakımından yakında ilişkilidir. DFM içerisinde bakterilerin dışında maya ve küflerinde ayrı bir yeri bulunmaktadır (Kocaoğlu ve Kara, 2009). 
Çizelge 1. Ruminant rasyonlarında DFM olarak kullanılan mikroorganizmalar.

\begin{tabular}{|c|c|}
\hline Cins (Genus) & Tür (Species) \\
\hline \multicolumn{2}{|c|}{ Laktik asit üreten bakteriler } \\
\hline \multirow[t]{14}{*}{ Lactobacillus } & Lactobacillus acidophilus \\
\hline & Lactobacillus casei \\
\hline & Lactobacillus cellobiosus \\
\hline & Lactobacillus curvatus \\
\hline & Lactobacillus delbrueckii \\
\hline & Lactobacillus fermentum \\
\hline & Lactobacillus helveticus \\
\hline & Lactobacillus lactis \\
\hline & Lactobacillus mesenteroides \\
\hline & Lactobacillus bulgaricus \\
\hline & Lactobacillus plantarum \\
\hline & Lactobacillus salivarius \\
\hline & Lactobacillus reuteri \\
\hline & Lactobacillus gallinarum \\
\hline \multirow[t]{8}{*}{ Bifidobacterium } & Bifidobacterium pseudolongum \\
\hline & Bifidobacterium longum \\
\hline & Bifidobacterium lactis \\
\hline & Bifidobacterium thermophilium \\
\hline & Bifidobacterium infantis \\
\hline & Bifidobacterium animalis \\
\hline & Bifidobacterium bifidum \\
\hline & Bifidobacterium adolescentis \\
\hline \multirow[t]{2}{*}{ Streptococcus } & Streptococcus bovis \\
\hline & Streptococcus faecium \\
\hline \multirow[t]{2}{*}{ Enterococcus } & Enterococcus faecium \\
\hline & Enterococcus faecalis \\
\hline \multicolumn{2}{|c|}{ Laktik Asit Kullanan Bakteriler } \\
\hline Megasphaera & Megasphaera elsdenii \\
\hline \multirow[t]{4}{*}{ Propionibacterium } & Propionibacterium shermanii \\
\hline & Propionibacterium freudenreichii \\
\hline & Propionibacterium acidipropionici \\
\hline & Propionibacterium jensenii \\
\hline \multicolumn{2}{|l|}{ Diğer Bakteriler } \\
\hline Prevotella & Prevotella bryantii \\
\hline \multirow[t]{5}{*}{ Bacillus } & Bacillus coagulans \\
\hline & Bacillus subtilis \\
\hline & Bacillus licheniformis \\
\hline & Bacillus lentus \\
\hline & Bacillus pumilus \\
\hline \multicolumn{2}{|l|}{ Mayalar } \\
\hline \multirow[t]{2}{*}{ Saccharomyces } & Saccharomyces cerevisiae \\
\hline & Saccharomyces boulardii \\
\hline \multicolumn{2}{|l|}{ Funguslar (Küfler) } \\
\hline \multirow[t]{2}{*}{ Aspergillus } & Aspergillus oryzae \\
\hline & Aspergillus niger \\
\hline
\end{tabular}




\section{DFM'NIN ETKINLİĞiNi VE AKTIVITESINi BELİRLEYEN FAKTÖRLER}

DFM 'ler toz, macun, jel, hap veya kapsül şeklinde bir çok formda mevcut olup, içme suyu, süt, süt ikame yeminde eritilerek veya yeme iyice karıştırılarak veya yemin üzerine serpilerek hayvanlara verilebilirler (Anonim, 2016).

DFM 'lerin etki gösterebilmeleri için rumeni geçerek ince bağırsaklara ulaşmaları gereklidir. DFM 'ler normal rumen $\mathrm{pH}$ sına karşın dayanıklı olmalarına rağmen, yüksek rumen asiditesi durumu, mikroorganizmaların pek çoğunun ölümüne neden olduğundan ince bağırsaklara ulaşamazlar. Bağırsaklara ulaşmayı başaran mikroorganizmalar, buradaki villuslara yerleşirler. Etkinliklerini tam olarak gerçekleştirebilmek için bağırsak lümeni yerine bağırsak epitheline kolonize olmaları gereklidir. Buradaki mikroorganizmalar, mukoz madde içindeki müsin maddesini enerji kaynağ 1 olarak kullanır ve mukoza yüzeyini örten bu salg1 içerisinde çoğalır (Karademir ve Karademir, 2003).

DFM 'lerin etkinliği ayrıca bunların ne zaman kullanıldığı ile de ilişkilidir. DFM nin rasyona ilavesi faydalı bakterilerin yenilenmesi ve hizla sindirim sisteminin dengeli mikroflorasına dönmesine yardımcı olur. DFM kullanımına en iyi yanıtlar aşağıdaki durumlarda kendini daha çarpıcı olarak gösterir. Örneğin, yeni doğan ruminantlar normal şartlarda faydalı mikroorganizmaları analarından veya çevrelerinden edinirler.Dolayısıyla, sindirimsistemininerkendönemde DFM ile faydalı bakterilerle tanışıp bunların kolonize olması arzu edilir. Ayrıca, sütten kesim döneminde sütten bitkisel orjinli yemlere olan geçiş sırasında yeterli düzeyde genç hayvanların sindirim sisteminin gelişmemesi durumunda yine DFM uygulaması ile istenen düzeyde faydalı mikroorganizmanın sindirim sistemine yerleşimi sağlanabilir. Bunlarla birlikte, taşıma, aşılama vs stres oluşturan koşullar hayvanları strese sokarak iştah azalmasına ve bunun sonucu olarak yem alımını ve sonuçta canlı ağılık artışının düşmesine neden olabilir. Söz konusu durumlarda DFM uygulamalarına hayvanların tepkisi en iyi bir şekilde gerçekleşmektedir. Antibiyotik tedavi durumlarında da sindirim kanalındaki Lactobacillus ve diğer faydalı mikroorganizmaların sayısı önemli ölçüde düşer. $\mathrm{Bu}$ durumlarda da DFM uygulamalarına en iyi yanıtların elde edilmesi söz konusudur (Anonim, 2016).
DFM 'lerin stabilitesi çok önemli bir konudur. İçersindeki mikroorganizmaların etkili olunacak hayvanlara canlı bir formda ulaştırılması gereklidir. $\mathrm{Bu}$ nedenle üretici firmaların saklama ve taşıma konularındaki tavsiyelerine uyulması gereklidir. Bir çok DFM ler kuru ve serin ortamlarda depolanıp taşınması, direkt gün 1şığına ve yüksek neme maruz kalmaması gereklidir. Paketleri açıldıktan sonra sıkıca kapatılarak kullanılmayan kısmın canlılığı korumalıdır. Demir ve bakır iyonları başta olmak üzere mineral madde premixleri, yüksek konsantrasyonlarda vitaminler (özellikle vitamin K), antibiyotikler ve bazı koruyucu maddeler ve bazı oksidatif ajanların da DFM üzerine olumsuz etkileri olduğu bildirilmiştir (Quigley, 2011).

\section{DFM'LERIN ETKİ MEKANIZMALARI}

DFM 'lerin etki mekanizmaları hakkında birçok görüş ileri sürülmekte olup bunların etkileri rumende ve rumen sonras1 gelen gastrointestinal sistemin alt bölümleri olmak üzere iki bölümde incelebilir.

\section{DFM'lerin Rumendeki Etki Mekanizmaları}

Genellikle bakteriyel DFM 'ler sindirim kanalının rumenden sonra gelen alt kisimlarda potansiyel olarak faydalı etkilere sahiptirler (Alp ve Kahraman, 1996). Ancak bazı bakteriyel DFM lerin rumende de fonksiyonel pozitif etkileri olduğu da tespit edilmiştir (Krehbiel et al., 2003). Bakteriyel DFM 'leri oluşturan mikroorganizmalardan, laktik asit üreten bakterilerin i) rumende devamlı ve sabit miktarda laktik asit üretimi, ii) ruminal mikroorganizmaların laktik asitin varlığına adapte olmaları, iii) laktik asit kullanan bakterilerin stimülasyonu, iv) ruminal $\mathrm{pH}$ nın stabilizasyonu yoluyla pozitif etkiyi sağladığı konusunda ileri sürülen mekanizmaların (Ghorbani et al., 2002; Beauchemin et al., 2003; Raeth-Knight et al., 2007) yanı sıra, laktik asit kullanan bakterilerin de i) laktik asidin uçucu yă asitlerine dönüştürülmesiyle (Megasphaera elsdenii) ii) laktik asit üretiminden ziyade propiyonik asit üretimiyle (Propionibacterium spp.), iii) yemden yaralanmanın iyileştirilmesiyle, iv) metan üretiminin azaltılmasıyla sağladığı bildirilmektedir (Hutjens, 2007). Fungal DFM lerin etki şekillerine ait ileri sürülen teoriler ise, söz konusu bu mikroorganizmalar faydalı etkilerini i) rumende oksijen seviyesinin düşürülmesiyle, ii) organik asitler ve $\mathrm{B}$ vitamini gibi büyüme faktörlerinin sentezini yaparak, iii) rumende 
mikroorganizma sayısını ve aktivitesini artırarak, iv) uçucu yağ asitleri, ruminal proteinler gibi ruminal son ürünlerde artış sağlayarak, v) rumende sidirilebilirlik oranında artış sağladığı bildirilmiştir (Dutta et al., 2009).

DFM 'ler içersinde laktik asit kullanan bakterilerin laktik asit konsantrasyonunu düşürdüğü ve ruminal pH y1 koruduğu bildirilmiştir. Örneğin Megasphaera elsdenii laktik asitten yararlanabilen bakterilerden olup ve yüksek oranda fermente olabilen nişasta, glukoz, sellobiyoz gibi maddeleri yüksek oranda içeren rasyonlarla yapılan beslemede rumende laktik asit birikimini önlediği ve hılı ve keskin $\mathrm{pH}$ düşüşünü önleyebildiği, ayrıca, Megasphaera elsdenii ilavesinin laktasyonun ilk dönemindeki hayvanlarda akut asidosisin önlenmesinde de etkili olabileceği Kung and Hession (1995) tarafından bildirilmiştir.

Propionibacteria laktik asidi propiyonik aside fermente eder ve laktasyonun ilk döneminde propiyonik asit glukoneojenesisin ana prokürsör maddesi olduğu için, rumende propiyonik asidin artışı hepatik glukoz üretimini de artırmaktadır (Weiss et al., 2008). Ayrıca, laktoz sentezi için artan glukoz miktarları \% 4,4 oranında enerjitik etkinliği artırdığ 1 ve ketosisi azalttığ 1 da Weiss et al., (2008) tarafından rapor edilmiştir.

Ruminant beslemede kullanılan maya içerikli DFM 'ler verimi pozitif yönde etkilediği gibi rumen fermentasyonunu da normalleştirir (Swartz et al., 1994). Mayaların rasyona ilavesi ile rumendeki bakteri sayısı önemli ölçüde artmaktadır. Karademir ve Karademir (2003) in bildirdiğine göre, mayalar rumendeki oksijeni kullanarak ortamdan uzaklaştırmakta, redoks potansiyelini düşürerek $(-20 \mathrm{mV}$ a kadar) aerobik patojenlerin oksijenden yararlanmalarını engellemekte ve gelişimlerini durdurmaktadır. Rumendeki değişim, sellulolitik bakterilerin gelişimi için mükemmel bir ortam oluşumunu sağlarken, bu bakterilerin kaba yeme yapışmalarını stimüle etmekte selülozun parçalanma hızını yükseltmektedir (Roger et al., 1990). Chaucheyras et al., (1995) da invitro olarak Saccharomyces cerevisiae' in ruminal bakterilerden Streptococcus bovis ve Megasphaera elsdeni ile birlikte laktik asit metabolizması üzerine etkilerini araştırdıkları bir çalışmada, Saccharomyces cerevisiae 'nın organik asitler ve vitaminler gibi büyüme faktörü sağlama yeteneğinde olduğunu ve bunun sonucu olarak sellulolitik ve laktik asit kullanan bakterilerin (Megasphaera elsdenii) rumen popülasyonunu stimüle ettiğini bildirmişlerdir.

\section{Bağırsaklarda DFM 'lerin Etki Mekanizmaları}

Bakteriyel DFM 'lerin ince bağırsak duvarında patojen mikroorganizmalarla kolonizasyon ve besin maddeleri açısından bir mücadele içersinde oluşu yönündeki düşünceler, DFM 'lerin söz konusu bölgede yaptığı etkileri açıklamaya yönelik ilk teoriyi oluşturmuştur. Konu ile ilgili ilk çalışmada Jones and Rutter (1972), diyareye neden olan ve enterotoksin üreten $E$. coli' nin şuşları için bağırsak duvarına tutunmanın çok önemli olduğunu ileri sürmüştür. $\mathrm{Bu}$ tutunma işleminin mikroorganizmaların çoğalmalarını artırmakta ve bağırsakların peristaltik hareketleri sonucun söz konusu mikroorganizmaların sindirim kanalından uzaklaştırılmasını azaltmaktadır (Salminen et al., 1996). Yapılan çalışmalarda bakteriyel DFM ilave edilen rasyonlarla beslenen buzağılarda ve domuz yavrularında yüksek miktarda Lactobacillus ve az sayıda ise $E$. coli 'ye rastlandığı Abu-Tarboush et al., (1996) tarafından bildirilmiştir. Lee et al., (2003) da L. rhamonsus' un hidrofobik interaksiyonla bağırsak epitel hücrelerine bağlandığını ve patojen mikroorganizmaların ince bağırsakların absortif kolumnar epitel yapısındaki hücrelerin reseptörlerine bağlanmalarını sınırladığı bildirmişlerdir. Ayrıca $L$. rhamonsus' un enteropatojenik ve enterotoksijenik E. coli ve Klebsiella pheumonia 'ların sindirim kanalına yapışmalarını azalttığı Forestier et al., (2001) tarafından da rapor edilmiştir.

İnce bağırsaklarda DFM 'lerin ortaya koydukları faydalı etkileri açıklamaya yönelik ileri sürülen ikinci mekanizma DFM 'lerin antibakteriyel etkileridir. Lactobacillus'ların bir çok türünün patojen mikroorganizmaların gelişimini önleyici (inhibitör) etkisi olduğu, örneğin Lactobacillus acidophilus'un enteropatojenik E. coli, Salmonella typhimurium, Staphylococcus aureus ve Clostridium perfringens 'e karş1 antagonistik etkiye sahip olduğu Blake and Clinton (2012) tarafından bildirilmiştir. Laktik asit üreten bakterilerin diğer bakterileri öldürmek için ürettikleri zehirli protein olan bakteriyosinler Cotter et al., (2005) tarafından ortaya konulmuştur. Anaerobik şartlarda glikoz ve gliserolün mevcut olduğu durumlarda Lactobacillus reuteri tarafindan üretilen reuterin hedef mikroorganizmaların ribonükleotid redüktaz'ın alt ünitesine substratların bağlanmasını engelleyerek söz konusu mikroorganizmaların DNA 
sentezini bozduğu Dobrogosz et al., (1989) tarafından bildirilmiştir. Ayrıca, laktik asidin gastrointestinal sistemdeki mevcudiyetinin ortamın $\mathrm{pH}$ sını düşürmesi nedeniyle bir çok patojen mikroorganizmanın çoğalmasını engellediği de ileri sürülmektedir (Karademir ve Karademir, 2003).

Laktik asit bakterileri tarafından üretilen hidrojen peroksit, patojen mikroorganizmalara karşı antogonistik reaksiyonlardan da sorumlu olabilecek diğer bir grup maddelerdir (Blake and Clinton, 2012).

Hidrojenperoksitin bakterisidal (bakteri öldürücü) aktivitesi olduğu, bakteri hücresini hücresel proteinlerde sülfidril grupları, membran lipidlerini okside ettiğini ve sonuçta glikoz transport enzimlerini, hekzokinaz, gliseraldehit-3-fosfat dehidrojenaz gibi metabolik enzimlerde sülfidril grupların oksidasyonu ile glikolisisi bloke ettiği Dicks and Botes (2010) tarafından bildirilmiştir. Bu konuda yapılan diğer bir çalışmada da Holzapfel et al., (1995) laktik asit bakterilerinin hidrojenperoksit ürettiğini ve bununda etkin bir şekilde Streptococcus aureus ve Pseudomonas spp. lerin gelişimini durdurduğunu ortaya koymuşlardır.

Konakçı hayvanın bağışıklık fonksiyonun değişimi, DFM 'ler tarafından oluşturulan sindirim sisteminin ve konakçının genel sağlığını ve performansını iyileştiren etki mekanizmalarından bir diğerini teşkil etmektedir (Blake and Clinton, 2012). Sindirim sisteminde makrofajlar, nötrofiller, doğal katil hücreler, dentrik hücreler, T ve B lenfositler gibi immün sistem hücreleri mevcuttur.

DFM ler sindirim sistemine alındığında endositoz yolu ile bağırsak epitel hücrelerine alınırlar. Hücrelere ulaşan antijenler, makrofajlar ve dentrik hücreler tarafindan yutulur ve bağışıklık sistemi uyarılır (Dicks and Botes 2010). Laktik asit üreten bakteriler bağışıklık sistemini stimüle eden sitokininleri üretmek üzere makrofajları harekete geçirir. $L$. casei ve $L$. rhamnosus un makrofajların TNF- $\alpha$ (tümör nekrosis faktör- $\alpha$ ) yı salgılamasını uyardığı ve düzenleyici dentrik hücrelerin gelişimini artırdığı Matsuguchi et al., (2003) tarafindan bildirilmiştir. Ayrıca, rasyon yolu ile alınan DFM lerin genellikle artan fagositoz ve doğal katil hücre aktiviteleriyle birlikte yükselen Immünglobülün $\mathrm{A}(\mathrm{Ig} \mathrm{A})$ ve azalan $\operatorname{IgE}$ üretimleri ile bağ 1 ş1klık sistemini etkiledikleri Krehbiel et al., (2003) tarafından rapor edilmiştir.

DFM 'lerin ince bağırsaklardaki bir diğer etki şeklinin konakçı hayvanın enzim aktivitelerini etkileyerek gerçekleştirdiği ileri sürülmüştür (Hutjens, 2007). Faydalı Bacillus spp. ler proteaz, amilaz, lipaz ve glikosidaz gibi çeşitli enzimler üretirler. DFM ler ayrıca ince bağırsaktaki toksik enzimlerin azaltılmasına da sebep olurlar. Bazı mikroorganizmalar tarafından üretilen aminler toksik etkili olup, isallerle yakından ilişkilidirler. Laktik asit bakterileri amin konsantrasyonunu azaltarak sindirim sistemindeki entero-toksinleri nötralize ederler.

\section{KAYNAKLAR}

Abu-Tarboush HM, Al-Saiady MY, Keir El-Din AH, 1996. Evaluation of diet containing lactobacilli on performance, fecal coliform, and lactobacilli of young dairy calves. Animal Feed Science and Technology, 57:39-49.

Alliance Animal Health, 2009. Direct fed microbial: Application and usage. Technical Bulletin.http://www.admani.com/ AllianceAnimalHealth/Tech\%20Bulletins/Direct $\% 20$ Fed $\% 20$ Microbials.htm. (Erişim tarihi: 5 Ocak, 2016).

Alp M, Kahraman R, 1996. Probiyotiklerin hayvan beslemede kullanılması. İstanbul Üniversitesi Veteriner Fakültesi Dergisi, 22:1-8.

Anonim, (2016). http://www.admani.com/animal\%20health/ Tech\%20Bulletins/Animal\%20Direct\%20fed \%20microbial. htm (Erişim tarihi: 15 Ocak, 2016).

Aydın R, Diler A, Yanar M, Koçyiğit R, Özkılıççı T, 2008. The effect of direct-fed microbials plus enzyme supplement on the growth performance of Holstein Friesian calves. Journal of Animal and Veterinary Advances, 7:516-519.

Beauchemin KA, Yang WA, Morgavi DP, Ghorbani, GR, Kautz B, 2003. Effects of bacterial direct-fed microbials and yeast on site and extent of digestion, blood chemistry and subclinical ruminal acidosis in feedlot cattle. Journal of Animal Science, 81:1628-1640.

Blake KW, Clinton RK, 2012. Direct-fed Microbials and Prebiotics for Animals. Science and Mechanisms of Action. Callaway, TR and Ricke SC (editors). Springer Science Business Media, New York, USA. 148 p.

Chaucheyras F, Fonty G, Bertin G, Salmon JM, Gouet P, 1995. Effects of a strain of Saccharomyces cerevisiae (Levucell SC), a microbial additive for ruminants, on lactate metabolism in vitro. Canadian Journal of Microbiology. 42:927-933.

Cotter P D, Hill C, Ross R P, 2005. Bacteriocins: Developing innate immunity for food. Nature Reviews Microbiology, 3:777-788

Dicks LMT, Botes, M. 2010. Probiotic lactic acid bacteria in the gastro-intestinal tract: Health benefits, safety and mode of action. Beneficial Microbes, 1:11-29.

Diler A, Koçyiğit R, Yanar M, Aydın R, 2015. Effect of feeding 
direct-fed microbials plus exogenous feed enzymes on milk yield and milk composition of Holstein Friesian cows. Veterinarija Ir Zootechnika, 65:11-16.

Dobrogosz, WJ, Casas IA, Pagano GA, Talarico TL, Sjöberg BM, Karlsson M, 1989. Lactobacillus reuteri and the enteric microbiota. In: The Regulatory and protective role of the normal microflora (Ed. E. Norin). Stockton Press. New York, USA. 283 p.

Dutta, TK, Kundu, SS, Kumar, M, 2009. Potential of direct-fedmicrobials on lactation performance in ruminants - A critical review. Livestock Researchfor Rural Development, 21: Article no:160. http://www.lrrd.org/lrrd21/10/dutt21160.htm. (Erişim tarihi: 5 Ocak, 2016).

Forestier C, Champs C, Vatoux C, Joly B, 2001. Probiotic activities of Lactobacillus casei rhamnosus: in vitro adherence to intestinal cells and antimicrobial properties. Research in Microbiology, 152:167-173.

Ghorbani GR, Morgavi DP, Beauchemin KA, Leedle AZ, 2002. Effects of bacterial direct-fed microbials on ruminal fermentation, blood variables and microbial populations of feedlot cattle. Journal of Animal Science, 80:1977-1985.

Holzapfel WH, Geisen R, Schillinger U, 1995. Biological preservation of foods with reference to protective cultures, bacteriocins and food-grade enzymes. International Journal of Food Microbiology, 24:343-362.

Hutjens MF, 2007. Direct Fed Microbial Products (DFM). http:// articles.extension.org/ pages/11314/direct-fed-microbialproducts-dfm. (Erişim tarihi: 5 Ocak, 2016).

Jones GW, Rutter JM, 1972. Role of K88 antigen in the pathogenesis of neonatal diarrhea caused by Escherichia coli in piglets. Infection and Immunity, 6:918-927.

Karademir G, Karademir B, 2003. Yem katk1 maddesi olarak kullanılan biyoteknolojik ürünler. Lalahan Hayvancılık Araştırma Enstitüsü Dergisi, 43:61-74.

Kocaoğlu B, Kara B, 2009. Ruminant beslemede alternative yem katk1 maddelerinin kullanımı:1. Probiyotik, prebiyotik ve enzim. Erciyes Üniversitesi Veteriner Fakültesi Dergisi, 6:6575.

Koçyiğit R, Aydın R, Yanar M, Güler O. Diler A, Tüzemen N, Avcı, M, Özyürek S, Hirik E, Kabakc1 D, 2015. Effect of doses of direct-fed microbials plus exogenous fibrolytic enzymes supplementation on growth, feed efficiency ratio and fecal consistency index of Brown Swiss and Holstein Friesian calves. Indian Journal of Animal Research, 49:63-69.

Krehbiel CR, Rust SR, Zhand G, Gilliand SE, 2003. Bacterial direct-fed microbials in ruminant diets: Performance response and mode of action. Journal of Animal Science (E.Suppl.2):E120-E132.

Kung L, Hession AO, 1995. Preventing in vitro lactate accumulation in ruminal fermentations by inoculation with Megasphaera elsdenii. 1995. Journal of Animal Science, 73:250-256.

Lee YK, Puong KY, Ouwehand AC, Salminen S, 2003. Displacement of bacterial pathogens from mucus and Caco-2 cell surface by lactobacilli. Journal of Medical Microbiology, 52:925-930.

Matsuguchi T, Takagi A, Matsuzaki T, Nagaoka M, Ishikawa K, Yokokura T, 2003. Lipoteichoic acids from Lactobacillus strains elicit strong tumor necrosis factor a-inducing activities in macrophage through toll-like receptor 2. Clinical and Diagnostic Laboratory Immunology, 10:259-266.

Newman KE, Jacques KA, 1995. Microbial feed additives for pre-ruminants. Biotechnology in animal feeds and animal feeding. RJ Wallance, A Chesson, (Editor). Wiley-Blackwell Publishing, Weinheim, Germany. 247 p.

Quigley J, 2011. Direct-fed microbials (probiotics) in calf diets. AFIA Publications. https://www.aphis.usda.gov/animal health/nahms/dairy/downloads/bamn/BAMN11_Probiotics. pdf (Erişim tarihi: 5 Ocak, 2016).

Raeth-Knight ML, Linn JG, Jung HG, 2007. Effect of direct-fed microbials on performance, diet digestibility, and rumen characteristics of Holstein dairy cows. Journal of Dairy Science, 90:1802-1809.

Roger, V., G. Fonty, S. Komisarczuk-Bony and P. Gouet. 1990. Effects of physicochemical factors on the adhesion to cellulose avicel of the ruminal bacteria Ruminococcus flavefaciens and Fibrobacter succinogenes subsp. succinogenes. Applied Environmental Microbiology, 56:3081-3087.

Salminen S, Isolauri E, Salimen E, 1996. Clinical uses of probiotics for stabilizing the gut mucosal barrier: successful strains and future challenges. Antonie van Leeuwenhoek Journal of Microbiology, 70:347-358.

Seo JK, Kim SW, Kim MH, Upadhaya SD, Kam DK, Ha JK, 2010. Direct-fed microbials for ruminant animals. Asian-Australian Journal of Animal Science, 23:1657-1667

Swartz DL, Muller LD, Rogers GW, Varga1 GA, 1994. Effect of yeast cultures on performance of lactating dairy cows: A field study. Journal of Dairy Science, 77: 3073-3080.

Weiss WP, Wyatt, DJ, Mc Kelvey TR, 2008. Effect of feeding propionibacteria on milk production by early lactation dairy cows. Journal of Dairy Science, 91:646-652.

Yoon IK, Stern MD, 1995. Influence of direct-fed microbials on ruminal microbial fermentation and performance of ruminants: A review. Asian-Australian Journal of Animal Science, 8:533-555. 